\title{
Comparative study of polyglactin 910 and simple catgut in the formation of intraperitoneal adhesions ${ }^{1}$
}

\author{
Maria de Lourdes Pessole Biondo-Simões', Marian Hanae Oda", Suzane Pasqual", Rogério Ribeiro \\ Robes
}

\begin{abstract}
'PhD, Associate Professor, Department of Surgery, Universidade Federal do Paraná (UFPR), Brazil. Intellectual and design of the study, analysis of data, manuscript writing, final approval the version to be published.

"Graduate student, Scientific Initiation Program, UFPR, Curitiba-PR, Brazil. Acquisition, analysis and interpretation of data; technical procedures, manuscript preparation.

'"Master, Full Professor, Department of Anesthesiology, Faculty of Veterinary Medicine, UFPR, Curitiba-PR, Brazil. Analgesia and post-operative care, manuscript writing.
\end{abstract}

\begin{abstract}
Purpose: To compare polyglactin 910 and simple catgut sutures for the incidence of intraperitoneal adhesions.

Methods: Twenty female Wistar rats were placed into two groups. Group 1 received ischemic sutures and Group 2 received polyglactin 910. Five sutures inductive of adhesions in each rat were made. After 14 days, the rats were euthanized with an assessment of the presence of adhesions, the number of sutures involved and classification according to the Granat et al. scale described by Ozel et al ${ }^{17}$.

Results: In total, 19 of the 20 rats presented adhesions, with nine from Group 1 and ten from Group 2. There was a smaller number of affected sutures in Group 1, while in Group 2 the majority of the sutures formed adhesions ( $p=0.0197)$. According to the Granat et al. scale, Group 1 predominately developed fine, filamentous adhesions or thickening in a restricted area. Group 2 mainly presented extensive, thick adhesions with the involvement of the viscera $(p=0.0055)$.
\end{abstract}

Conclusion: Polyglactin 910 sutures formed more adhesions that were more extensive and thicker than the simple catgut sutures.

Key words: Tissue Adhesions. Peritoneum. Sutures. Polyglactin 910. Catgut. Rats. 


\section{Introduction}

By adhesion we understand fibrotic bands of scar tissue, frequently a consequence of surgery, that form between internal organs, joining them to one another or to the parietal peritoneum ${ }^{1}$.

Incidence reaches $93 \%$ in post abdominal surgery patients, and up to $97 \%$ for pelvic surgery. In autopsy studies of patients with previous laparotomy, the incidence varied between 70 and $90 \%{ }^{2}$. They are responsible for $32 \%$ of acute intestinal obstructions and for 65 to $75 \%$ of small intestinal obstructions ${ }^{3}$. When there is need for surgical intervention, between 5.7 and $23.2 \%$ of patients require intestinal resections ${ }^{4}$.

Amongst the possible causes for the formation of adhesions are: tissue trauma, the use of electrocautery, abrasions, ischemia and the presence of foreign bodies that can include talcum from gloves or synthetic sutures ${ }^{2,5,6}$.

Ischemia has been identified as the main agent responsible for adhesions ${ }^{7}$. Operations include various causes of ischemia such as: diastasis, hemostasis (ligatures and electrocoagulation, ultrasonic tissue section, laser energy), synthesis (with more or less tension), foreign bodies (material used for ligatures and syntheses) and pressure causing damage to the peritoneum ${ }^{8}$.

The formation of adhesions is associated with the coating on the surface of the peritoneum and to its high capacity for remesothelization. Lesions in the peritoneum, function as a trigger for pro-coagulative states. Initially, messengers are released at the lesion site. This triggers a cascade of events mediated by leukocytes, mesothelial cells and fibrin ${ }^{2,5,6}$.

Subsequently, macrophages release substances such as: cyclooxygenase, plasminogen activator, plasminogen activator inhibitor, collagenase, elastase, tumor necrosis factor, interleukins 1 and 6, leukotrienes, prostaglandins, etc. Additionally, the macrophages recruit mesothelial cells that will respond to the cytokines and initiate remesothelization. An important step for the formation of adhesions is the transformation of the fibrinogen into insoluble fibrin, which interacts with the proteins to form the fibrin gel matrix ${ }^{2,5,6}$.

The balance between the deposition of fibrin and its degradation is crucial for the determination of the normal scarring of the peritoneum or for the formation of adhesions. Incomplete degradation serves as a basis for the growth of fibroblasts and capillaries with the formation of permanent adhesions ${ }^{5}$.

Early fibrinolysis, within five days, stimulates scarring of the peritoneum without adhesions between the tissues ${ }^{6,9}$. If this does not take place, the temporary matrix persists and gradually organizes. The fibroblasts begin to secrete collagen making the adhesion permanent ${ }^{9.10}$.

Various animal models have been used to understand the process of the formation of adhesions. Only starting from an understanding of its origins can we act with preventative mechanisms. Models for induction of adhesion with suture, electrocoagulation, ischemic buttons, foreign bodies, etc ${ }^{11}$ were studied.

Considering that the most frequent peritoneal lesion is the surgical incision and synthesis using different suture types, the model of the ischemic peritoneal lesion with foreign body has been the most common ${ }^{11,12}$.

In Brazil, the most used thread for the peritoneal synthesis has been simple catgut and polyglactin 910. Simple catgut thread is an absorbable organic thread that is absorbable through inflammatory reaction and enzymatic breakdown. Polyglactin 910 is an absorbable synthetic thread that is absorbable via hydrolysis ${ }^{13}$. Simple catgut is absorbed completely in around 70 days and loses $70 \%$ of its tensile force within seven days. By comparison, polyglactin 910 shows complete 
absorption between 56 and 70 days and loses $50 \%$ of its tensile force within three weeks ${ }^{14}$.

There is no consensus regarding the formation of adhesions specifically related to these materials. While some show that the polyglactin 910 led to a lower incidence of adhesions ${ }^{15,16}$, others showed that it led to a higher incidence ${ }^{13}$.

The objective of the present study is to compare polyglactin 910 and simple catgut for the incidence of peritoneal adhesions.

\section{Methods}

The study was developed following the analysis and consideration of the Ethics Commission for the use of Animals of the Biological Sector of the Universidade Federal do Paraná and approved on the 10/5/2016 in the process 23075.122970/2016-62. The norms contained in the Federal Law no $11.794 / 2008$ and the guidelines from the Brazilian Guidelines for the Care and Use of Animals for Scientific and Educational Purposes (2013) were followed.

Twenty female Wistar rats (Rattus norvegicus albinus, Rodentia mammalia) between 100 and 120 days old with an average weight of $245 \pm 38$ grams were used. They were sourced from the Bioterio Central at the Universidade Federal do Paraná, and maintained in an animal facility with a lightdark cycle, appropriate temperature and humidity and commercial feed and water ad libitum.

The rats were anesthetized under the supervision of a veterinary doctor with $0.1 \mathrm{ml} / 100 \mathrm{~g}$ of weight with a mixture of $1 \mathrm{ml}$ of ketamine $(50 \mathrm{mg})$ and $0.5 \mathrm{ml}$ of xylazine $(20 \mathrm{mg})$. The anesthesia was completed with isoflurane via facial mask with spontaneous respiration. Subsequently, the ventral abdominal wall was shaved and polyvinylpyrrolidone-iodine antiseptic applied.
An average laparotomy of approximately five centimeters was performed. The rats were randomized into two groups: Group 1 (G1), whose foreign body was simple catgut and Group 2 (G2), whose foreign body was polyglactin 910 .

To obtain the inductive sutures for the adhesions, muscular-peritoneal fixing and traction using a Halstead clamp was performed. The base of the traction tissue was joined with 4.0 simple catgut thread or 4.0 polyglactin 910 thread. Five inductive sutures for adhesion were made on the peritoneal surface, to the left of the midline, parallel to the incision, at one centimeter distance from the latter, and separated from each other by one centimeter. The procedure resulted in an ischemic 'polypoid' area of more or less $3 \mathrm{~mm}$, associated with the foreign body.

Following this, the continuous synthesis of the peritoneal-muscular-aponeurotic plane and skin with 4.0 monofilament nylon thread was performed.

Post-operatively, the rats immediately received $10 \mathrm{mg} / \mathrm{kg}$ of dipyrone, intramuscularly for analgesia. The animals were placed in boxes where they were given water and food ad libitum until the moment of euthanasia, which took place 14 days later. The veterinary doctor realized the euthanasia following the guidelines of the Resolution no $1000 / 2012$ of the Federal Council of Veterinary Medicine. The opening of the abdominal cavity was made with a $U$ incision, with a lateral base, which when raised allowed the evaluation of the adhesions.

The analysis of the results was performed with the verification of the presence, or not, of adhesions under the sutures, number of sutures affected and the evaluation of the adhesions according to the Granat et al. scale described by Ozel et al. ${ }^{17}$. Finally, the abdominal wall was dried and the material stored in $10 \%$ formaldehyde for continuation of the study in the same area of research (Chart 1). 
Chart 1 - Granat et al. Scale.

\begin{tabular}{ll}
\hline Score & Characteristics \\
\hline 0 & Absence of adhesions \\
1 & $\begin{array}{l}\text { Fine, filamentous, easily separable } \\
\text { adhesions }\end{array}$ \\
2 & Thick adhesions in a limited area \\
3 & Thick, extensive adhesions \\
4 & $\begin{array}{l}\text { Thick, extensive adhesions including } \\
\text { viscera }\end{array}$ \\
\hline
\end{tabular}

Source: Ozel et al. ${ }^{17}$

All the data was obtained by the researchers and recorded using the data collection instrument. It was entered into an electronic spreadsheet (Microsoft Excel $^{\circ}$ ), reviewed and exported for subsequent statistical analysis (Statistica - Statsoft ${ }^{\circ}$ version 8.0).

The statistical analysis was performed using the Fisher exact nonparametric test. $\mathrm{p} \leq 5 \%$ or 0.05 was established as the level for the rejection of the null hypothesis.

\section{- Results}

Throughout the experiment, there were no post-operative complications or deaths. In total, 19 rats developed adhesions, with nine from Group 1 and ten from Group 2 (Table 1). Only one rat did not present adhesions after the procedure, with its ischemic sutures being simple catgut thread (Figure 1).
Table 1 - Presence or absence of adhesions.

\begin{tabular}{llll}
\hline Adhesions & Yes & No & Total \\
\hline Simple catgut & 9 & 1 & 10 \\
Polyglactin 910 & 10 & 0 & 10 \\
Total & 19 & 1 & 20 \\
\hline
\end{tabular}

Exact Fisher test $>p=0.9999$

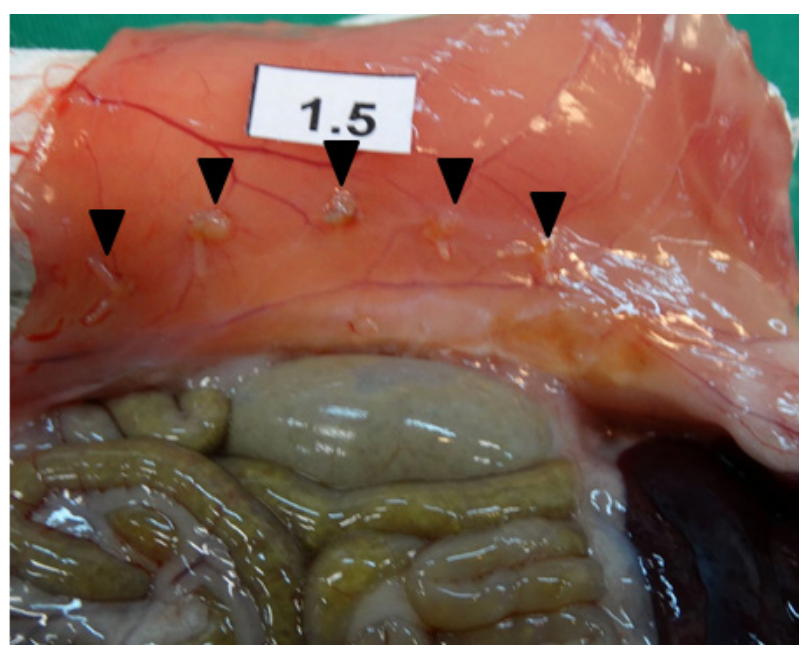

Figure 1 - Representation of five ischemic sutures of simple catgut without adhesions (black arrows).

In Group 1, there was a lower number of sutures affected (mainly up to three sutures), while in Group 2 the majority of the sutures formed adhesions (mainly four to five sutures), ( $p \leq 0.05)$ (Table 2). Only one rat presented less than three sutures with adhesions in the group with polyglactin 910 . This thread was observed forming more adhesions, affecting four or fewer of all the ischemic sutures with adhesions (Figure 2).

Table 2 - Number of affected sutures.

\begin{tabular}{llll} 
Number of sutures & Up to $\mathbf{3}$ sutures & $\mathbf{4}$ or $\mathbf{5}$ sutures & Total \\
\hline Simple catgut & 7 & 3 & 10 \\
Polyglactin 910 & 1 & 9 & 10 \\
Total & 8 & 12 & 20 \\
\hline
\end{tabular}

Exact Fisher test $>p=0.0197$ 


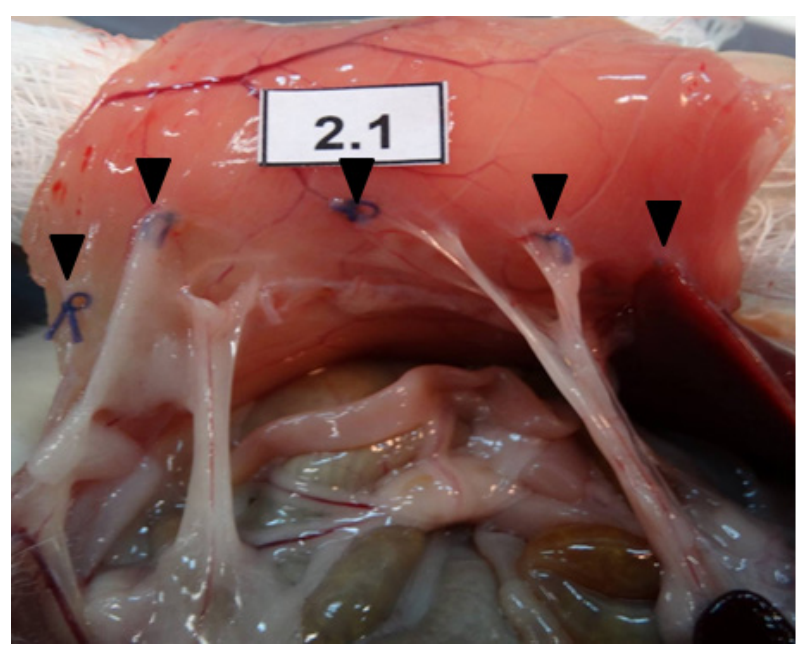

Figure 2 - Representation of five ischemic polyglactin 910 sutures with adhesions (black pointers).

According to the Granat et al. Scale described by Ozer et al. ${ }^{17}$, Group 1 developed more fine, filamentous or thick adhesions in a limited area (Figure 3). Group 2 mainly presented thick, extensive adhesions with involvement of viscera ( $p \leq 0.05)$ (Table 3). In all the cases in which viscera were affected, the organ affected was the liver (Figure 4).

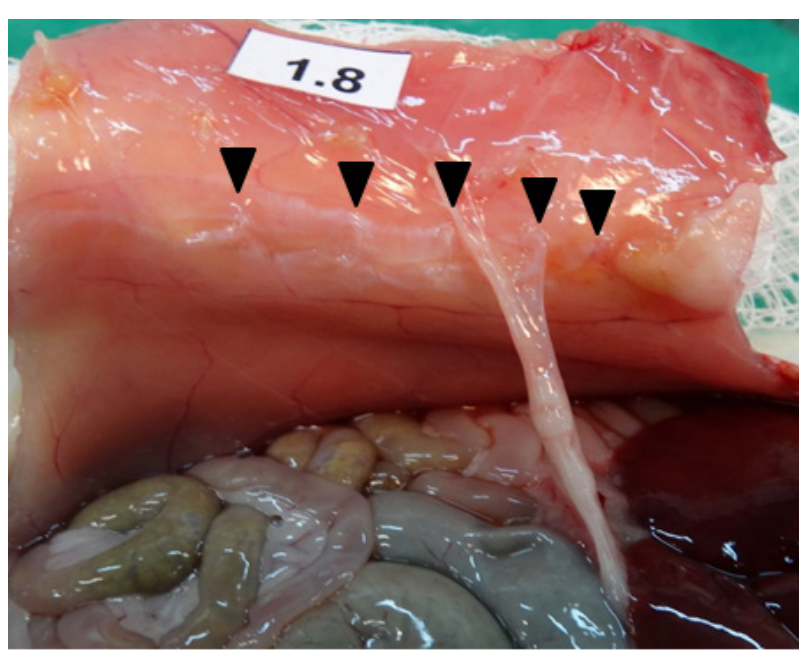

Figure 3 - Representation of five ischemic sutures with simple catgut, two stitches developed a fine, filamentous adhesion (black arrows).

Table 3 - Classification on the Granat et al. Scale

\begin{tabular}{llll}
\hline Score & From $\mathbf{0}$ to $\mathbf{2}$ & $\mathbf{3}$ or $\mathbf{4}$ & Total \\
\hline Simple catgut & 8 & 2 & 10 \\
Polyglactin 910 & 1 & 9 & 10 \\
Total & 9 & 11 & 20 \\
\hline
\end{tabular}

Granat et al Scale: 0- Absence of adhesions, 1- Fine, filamentous, easily separable adhesions 2- Thick adhesions in a limited area, 3Thick, extensive adhesions, 4- Thick, extensive adhesions including viscera (Exact Fisher test $>p=0.0055$ ).

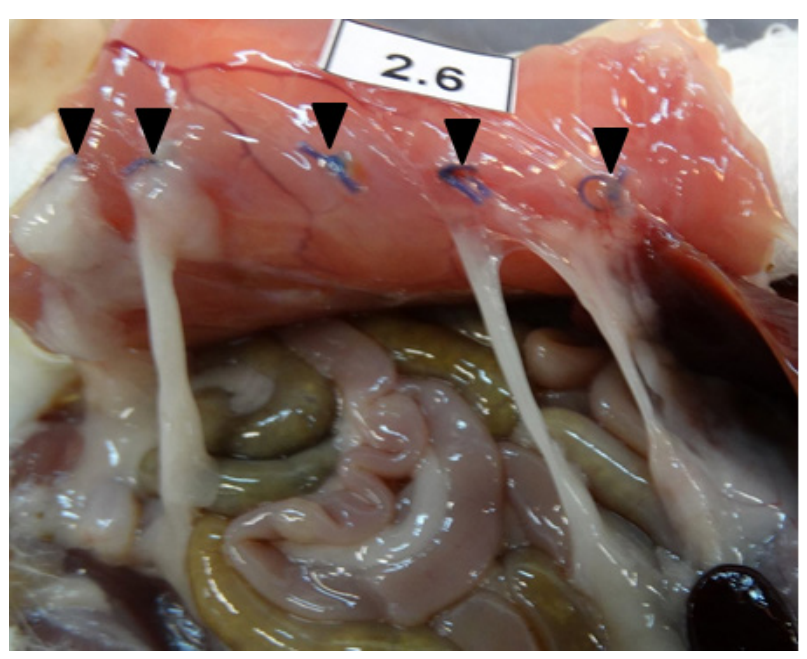

Figure 4 - Representation of five ischemic sutures with polyglactin 910, four sutures present adhesions and the last stitch enveloped the liver (black arrows).

\section{Discussion}

Intraperitoneal adhesions cause an increase in morbidity and are associated with various complications that can manifest even years after the surgical procedure ${ }^{18}$. Amongst these, the most common is obstruction of the small intestine, being responsible for $60-70 \%$ of the obstructions in this area ${ }^{19}$. Additionally, they are one of the main causes of secondary infertility ${ }^{20}$. Those located in the pelvis were responsible for $15-40 \%$ of cases of infertility ${ }^{21}$. Amongst surgical procedures, the colorectal type causes the most intra-abdominal adhesions $^{22}$.

Another problem stemming from 
adhesions is compromising reoperation, making it difficult and adding time to the surgery. It also increases the risk of istrogenic intestinal lesions and makes laparoscopic approaches difficult or even impossible ${ }^{23}$. Adhesion has also been investigated as a cause of chronic pelvic pain $^{24}$. As well as restricting the movement of the organs and tensing the smooth muscle of adjacent organs, the adhesions themselves can generate pain ${ }^{25}$. Post-operative adhesions have a significant economic impact requiring surgical procedures, with hospitalization, recovery and representing a loss in productivity ${ }^{26}$.

Prior diseases such as diabetes, malnutrition, bacterial infections and the expansion of peritoneal trauma are some factors that can influence the formation of adhesions $^{8}$. Amongst the possible causes, ischemia is considered the main agent responsible for adhesions ${ }^{7}$. The most frequent peritoneal lesion is the surgical incision and synthesis with different types of suture. However, there are still many divergences in the literature regarding the formation of adhesions by polyglactin 910 and simple catgut.

Polyglactin 910 resulted in fewer adhesions in some studies. In these, a lower incidence of adhesions was reported when compared with the polydioxanone ${ }^{15}$ (an absorbable synthetic thread with polyglactin 910) while others concluded that polyglactin 910 results in lower chronic inflammation and fibrosis ${ }^{16}$. On the other hand, in one experimental model, this thread presented lower values for resistance to force of rupturing in rats ${ }^{13}$. Additionally, Neff et al. ${ }^{27}$ observed no statistically significant difference between polyglactin 910 and polydioxanone.

Simple catgut showed the formation of more extensive adhesions than polyglactin $910^{28}$. There is little information regarding simple catgut, however in the few experimental models conducted this thread produced more adhesions $^{29,30}$. Currently, there is a greater preference for absorbable synthetic thread, which reduces the number of recent studies regarding simple catgut. Additionally, there is interest from the pharmaceutical industry in synthetic thread, given that catgut has low commercial value, which may not stimulate much research regarding this material.

The greater involvement of ischemic knots and the greater extension of adhesions with the polyglactin 910 contradicts the data from the literature already presented. Catgut and the polyglactin 910 have similar absorption times. The breakdown mechanism for catgut is inflammatory. However, it is notable that polyglactin thread, despite having a hydrolysis breakdown mechanism, is a foreign body that stimulates an initial inflammatory response that can affect the formation of adhesions ${ }^{23}$.

The tensile force of these threads can also be considered. Simple catgut loses $70 \%$ of its force in seven days and polyglactin 910 loses $50 \%$ of its force in three weeks ${ }^{20}$. The fact that polyglactin 910 thread maintains its tensile force for longer in the tissue, maintaining the ischemia mechanism, can influence the greater number of adhesions that this thread forms compared with simple catgut, given that ischemia has an important role in the formation of adhesions ${ }^{11}$. Despite this, further research needs to be conducted to investigate the reasons why simple catgut thread forms a lower number of adhesions than polyglactin 910, mainly for relevance regarding the reduction in the number and extension of adhesions and given the economic advantages, taking into account the lower cost of simple catgut.

\section{- Conclusion}

The ischemic sutures with polyglactin 910 form more adhesions that were more extensive and thicker than those with simple catgut in rats. 


\section{References}

1. Sikirica V, Bapat B, Candrilli SD, Davis $K L$, Wilson $M$, Johns $A$. The inpatient burden of abdominal and gynecological adhesiolysis in the US. BMC Surg. 2011;11(1):13. doi: 10.1186/1471-2482-11-13.

2. Liakakos T, Thomakos N, Fine PM, Dervenis C, Young RL. Peritoneal adhesions: etiology, pathophysiology, and clinical significance. Recent advances in prevention and management. Dig Surg. 2001;18(4):260-73. doi: 10.1159/000050149.

3. Ouaïssi $M$, Gaujoux $S$, Veyrie $N$, Denève E, Brigand C, Castel B, Duron JJ, Rault A, Slim K, Nocca D. Post-operative adhesions after digestive surgery: Their incidence and prevention: Review of the literature. J Visc Surg. 2012;149(2):e104-14. doi: 10.1016/j. jviscsurg.2011.11.006.

4. Miller G, Boman J, Shrier I, Gordon PH. Natural history of patients with adhesive small bowel obstruction. $\mathrm{Br} J$ Surg. 2000;87(9):1240-7. doi: 10.1046/j.13652168.2000.01530.x.

5. Arung W, Meurisse $M$, Detry $O$. Pathophysiology and prevention of postoperative peritoneal adhesions. World J Gastroenterol. 2011;17(41):4545. doi: 10.3748/wjg.v17.i41.4545.

6. Schnüriger $B$, Barmparas G, Branco BC, Lustenberger T, Inaba K, Demetriades D. Prevention of postoperative peritoneal adhesions: a review of the literature. Am J Surg. 2011;201(1):111-21. doi: 10.1016/j. amjsurg.2010.02.008.

7. Alpay Z, Saed G, Diamond M. Postoperative adhesions: from formation to prevention. Semin Reprod Med. 2008;26(4):313-21. doi: 10.1055/s-0028-1082389.

8. Brüggmann $D$, Tchartchian $G$, Wallwiener M, Münstedt K, Tinneberg H-R, Hackethal A. Intra-abdominal adhesions: definition, origin, significance in surgical practice, and treatment options. Dtsch Arztebl In. 2010;107(44):769-75. doi: 10.3238/ arztebl.2010.0769.

9. Sulaiman H, Dawson L, Laurent GJ, Bellingan GJ, Herrick SE. Role of plasminogen activators in peritoneal adhesion formation. Biochem Soc Trans. 2002;30(2):126-31. doi: 10.1042/bst0300126.

10. Holmdahl L, Ivarsson M. The role of cytokines, coagulation, and fibrinolysis in peritoneal tissue repair. Eur J Surg. 1999;165(11):10129. doi: 10.1080/110241599750007810.

11.Kraemer B, Wallwiener C, Rajab TK, Brochhausen $C$, Wallwiener $M$, Rothmund R. Standardised models for inducing experimental peritoneal adhesions in female rats. Biomed Res Int. 2014;2014:1-8. doi: 10.1155/2014/435056.

12. Rajab TK, Kraemer B, Petri N, Brochhausen C, Schmitt VH, Wallwiener M. Intra-operative locally injected pharmacotherapy as a novel strategy for adhesion prophylaxis. Int J Surg. 2012;10(9):489-92. doi: 10.1016/j. ijsu.2012.07.003.

13.Valle LFC, Martins EA, d'Acampora AJ, Kestering DM, Sakae TM, Russi RF. Estudo da força de ruptura do plano músculoaponeurótico da parede abdominal após sutura em pontos separados comparando três tipos de fios cirúrgico em ratos Wistar. ACM Arq Catarin Med. 2007;36(1):51-8.

14.Singh S, Maxwell D. Tools of the trade. Best Pract Res Clin Obstet Gynaecol. 2006;20(1):41-59. doi: 10.1016/j. bpobgyn.2005.09.008.

15. Ishikawa K, Sadahiro S, Tanaka Y, Suzuki T, Kamijo A, Tazume S. Optimal sutures for use in the abdomen: an evaluation based on the formation of adhesions and abscesses. Surg Today. 2013;43(4):412-7. doi: 10.1007/ s00595-012-0249-y.

16. Whitfield RR, Stills HF, Huls HR, Crouch JM, Hurd WW. Effects of peritoneal closure and suture material on adhesion formation in a rabbit model. Am J Obstet Gynecol. 2007;197(6):644.e1-5. doi: 10.1016/j. ajog.2007.08.022.

17.Ozel H, Avsar FM, Topaloglu S, Sahin M. Induction and assessment methods used in experimental adhesion studies. Wound Repair Regen. 2005 Jul 6;13(4):358-64. doi: 10.1111/j.1067-1927.2005.130402.x.

18.Parker MC. Epidemiology of adhesions: the burden. Hosp Med. 2004;65(6):330-6. doi: 10.12968/hosp.2004.65.6.13729.

19.Parker MC, Ellis H, Moran BJ, Thompson JN, Wilson MS, Menzies D, McGuire A, Lower AM, Hawthorn RJ, O'Briena F, Buchan $S$, Crowe AM. Postoperative adhesions: ten-year follow-up of 12,584 patients undergoing lower abdominal surgery. Dis Colon Rectum. 2001;44(6):822-9. doi: 
10.1007/BF02234701.

20.Marana R, Rizzi M, Muzii L, Catalano GF, Caruana P, Mancuso S. Correlation between the American Fertility Society classifications of adnexal adhesions and distal tubal occlusion, salpingoscopy, and reproductive outcome in tubal surgery. Fertil Steril. 1995;64(5):924-9. doi: 10.1016/S00150282(16)57903-5.

21.Vrijland WW, Jeekel J, van Geldorp HJ, Swank DJ, Bonjer HJ. Abdominal adhesions: intestinal obstruction, pain, and infertility. Surg Endosc Other Interv Tech. 2003;17(7):1017-22. doi: 10.1007/s00464002-9208-9.

22.Lower AM, Hawthorn RJ, Ellis $\mathrm{H}, \mathrm{O}^{\prime}$ Brien $F$, Buchan S, Crowe AM. The impact of adhesions on hospital readmissions over ten years after 8849 open gynaecological operations: an assessment from the Surgical and Clinical Adhesions Research Study. BJOG. 2000;107(7):855-62. doi: 10.1111/ j.1471-0528.2000.tb11083.x.

23.Coleman MG, McLain AD, Moran BJ. Impact of previous surgery on time taken for incision and division of adhesions during laparotomy. Dis Colon Rectum. 2000;43(9):1297-9. PMID: 11005501.

24.Goldstein DP, deCholnoky C, Emans SJ, Leventhal JM. Laparoscopy in the diagnosis and management of pelvic pain in adolescents. J Reprod Med. 1980;24(6):2516. PMID: 6448296.
25.Sulaiman H, Gabella G, Davis MSc C, Mutsaers SE, Boulos P, Laurent GJ, Herrick $\mathrm{SE}$. Presence and distribution of sensory nerve fibers in human peritoneal adhesions. Ann Surg. 2001;234(2):256-61. PMID: 11505072.

26. Ray NF, Denton WG, Thamer M, Henderson SC, PerryS. Abdominal adhesiolysis: inpatient care and expenditures in the United States in 1994. J Am Coll Surg. 1998;186(1):1-9. doi: 10.1016/S1072-7515(97)00127-0.

27.Neff MR, Holtz GL, Betsill WL. Adhesion formation and histologic reaction with polydioxanone and polyglactin suture. Am J Obs Gynecol. 1985;151(1)20-3. doi: 10.1016/0002-9378(85)90416-8.

28.Bakkum EA, Dalmeijer RAJ, Verdel MJC, Henna J, Blitterswijk CA Van, Trimbos JB. Quantitative analysis of the inflammatory reaction surrounding sutures commonly used in operative procedures and the relation to postsurgical adhesion formation. Biomaterials. 1995;16(17):1283-9. doi: 10.1016/0142-9612(95)91042-W.

29. Winston RML. Microsurgical reanastomosis of the rabbit oviduct and its functional and pathological sequelae. Br J Obstet Gynaecol. 1975 Jul;82(7):513-22. PMID: 1148136.

30. Leary DPO, Coakley JB. The influence of suturing and sepsis on the development of postoperative peritoneal adhesions. Ann R Coll Surg Engl. 1992;74:134-7. PMID: 1567133.

\section{Correspondence:}

Maria de Lourdes Pessole Biondo-Simões

Rua Ari José Vale, 459

82030-025 Curitiba - PR Brasil

Tel.: (55 41) 9991-5566 / 3297-4359

malubiondo@gmail.com

Received: Oct 16, 2017

Review: Dec 18, 2017

Accepted: Jan 19, 2018
Conflict of interest: none

Financial source: none

\begin{abstract}
${ }^{1}$ Research performed at Department of Surgical Technique and Experimental Surgery, Universidade Federal do Paraná (UFPR), Curitiba-PR, Brazil.
\end{abstract}

